\section{Target Animal Safety and Residual Study for Berberine and other Phytogenic Compounds in Broiler Chickens}

\section{Abstract}

Background: Phytogenic compounds are one of many alternatives to current industry feed ingredients for the poultry industry. However, despite increased reports on the activity of phytogenic compounds against disease in poultry, there is a lack of data regarding safety and residual toxicity. This two-part study investigated the general health of broiler chickens fed Berberine, Ursolic Acid, Piceid, Honokiol and Baicalin in-feed at three different levels, and assessed the poultry tissue residue of Berberine in breast muscle, upper and lower thigh, and liver through LC/MS-MS.

Methods and Findings: Phase 1 trial results demonstrated that all birds appeared normal, with all gastrointestinal histologic lesions and liver histologic lesions identified within normal limits for broiler chickens in a production environment. Phase 2 trial showed that the lowest amount of Berberine, $0.03 \mathrm{~g} / \mathrm{kg}$ in-feed, resulted in tissue residues below the lower limit of detection $(<2 \mathrm{ng} / \mathrm{g})$, and the highest amount of Berberine, $0.3 \mathrm{~g} / \mathrm{kg}$ in-feed, yielded detectable values, although the significance of these results is still not clear.

Conclusions: In conclusion, the present study suggests that the five tested phytogenic compounds are safe for use in starter, grower and finisher feeds for broiler chickens. Further exposure and risk assessment calculations regarding appropriate residue levels are necessary to evaluate the use of Berberine as a feed ingredient for poultry.

Received: October 25, 2017; Accepted: December 07, 2017; Published: December 15, 2017

\section{Abbreviations}

BW: Body Weight; FCR: Feed Conversion Ratio; LC/MS-MS: Liquid Chromatography Tandem-Mass Spectrometry; LLOD: Lower Limit of Detection; LLOQ: Lower Limit of Quantification

\section{Introduction}

In recent decades, phytogenic compounds have become increasingly examined as alternatives to antibiotics in feed for the livestock industry. The need to replace antibiotics in animal production has been driven by the threat of antimicrobial resistance and the development of 'superbugs'. A recent review on antimicrobial resistance states that over $70 \%$ of medically important antibiotics in the US are sold for use in animals, with the primary use being for prevention of disease and increase of feed conversion efficiency, rather than treatment of sick animals

\section{David Xiang $\mathrm{Yu}^{1}$, Zhiyong He ${ }^{1,2}$, Colin Pouton ${ }^{3}$, Frederic J. Hoerr ${ }^{4}$ and Zhi-cheng Xiao ${ }^{1,2 *}$}

\section{Department of Anatomy and Developmental Biology, Monash University, Melbourne, Australia \\ 2 iRiccorgpharm Pty Ltd, Melbourne, Australia \\ 3 Department of Drug Delivery, Disposition and Dynamics, Monash University, Melbourne, Australia \\ 4 Veterinary Diagnostic Pathology, Virginia, USA}

*Corresponding author: Zhi-cheng Xiao

" zhiyong.he2@monash.edu

Department of Anatomy and Developmental Biology, Monash University, Melbourne, Australia.

Tel: 0420414411

Citation: Yu DX, He Z, Pouton C, Hoerr FJ, Xiao ZC (2017) Target Animal Safety and Residual Study for Berberine and other Phytogenic Compounds in Broiler Chickens. Arch Clin Microbiol. Vol.8 No.6:69

[1]. Hence, the identification and development of alternatives that do not hinder productivity is vital for the economic state of livestock industry and in the battle against antimicrobial resistance.

Berberine is an isoquinoline quaternary alkaloid and has been identified as the major active component of many plants such as Hydrastis canadensis (goldenseal) and B. vulgaris (barberry) and Coptis chinensis (Chinese goldthread) [2-4]. It has been used for thousands of years in traditional medicines for the treatment of intestinal maladies in humans [5]. The last decade has seen researchers investigate the potential of berberine for poultry use, reporting positive outcomes for the control of 
Fowl Cholera, Coccidiosis and Necrotic Enteritis (Figure 1) [69]. However, despite the reduction of harmful gut bacteria and improved outcomes reflected in bodyweight, feed conversion ratio and mortality, Berberine remains a contentious phytogenic compound due to the extensive literature regarding its toxicity [10]. Treated birds have been observed to have bloody diarrhea which may be indicative of damage to the absorptive mucosal surface [8].

Ursolic acid, Piceid, Honokiol and Baicalin are four other compounds identified to be commercially appropriate and feasible for practical use. Ursolic acid has been shown to improve bodyweight and feed efficiency in poultry [11]. It has also been reported to help control Salmonella in poultry and mice $[12,13]$. Piceid is a major derivative of resveratrol and is well-documented to be a natural antioxidant and confer beneficial effects on feed utilization, immunity, oxidative status, egg quality criteria and productive performance [14-16]. Similarly, Honokiol and Baicalin have been studied for their promotion of health, most notably on intestinal and liver health $[17,18]$.

Studies have demonstrated that phytogenic compounds such as the aforementioned have the potential to be used as alternatives for in-feed antibiotics in poultry. They are known to support multiple modes of action such as antimicrobial, antioxidative, immunomodulatory and anti-inflammatory, which makes it difficult for bacteria to develop an effective resistance

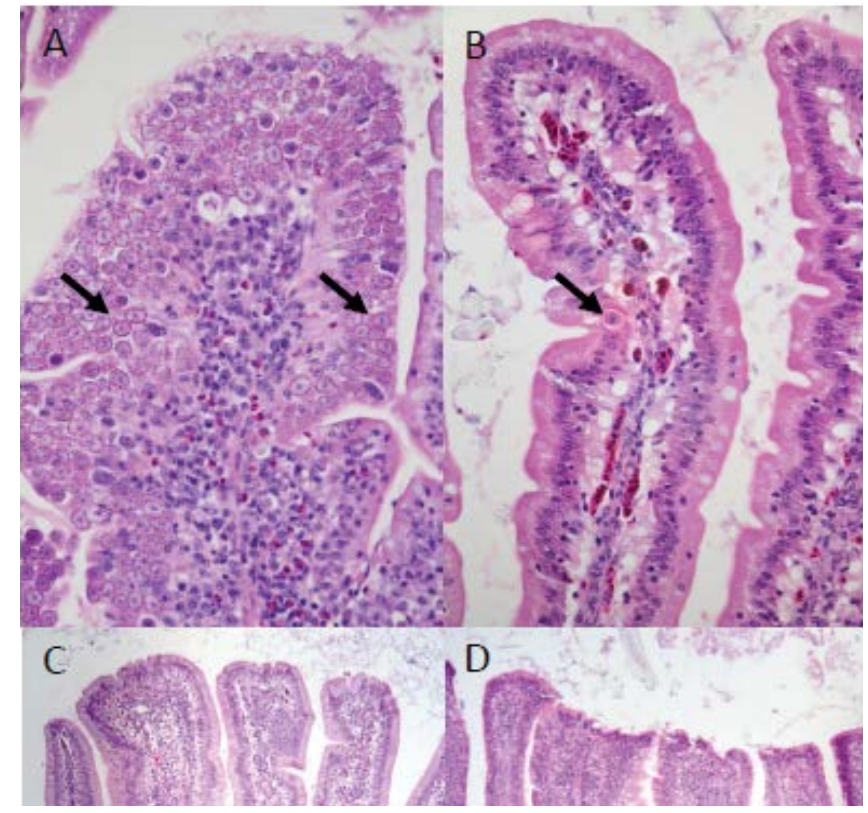

Figure 1 Coccidiosis and enteritis occurred in controls and treated chickens, but were less severe in some treated groups. A) Control duodenum, moderate Eimeria acervulina (arrows). B) Group 13, Honokiol $0.6 \mathrm{~g} / \mathrm{kg}$, minimal Eimeria acervulina (arrow). C) Control jejunum mild crypt hyperplasia (double arrow), a lesion included in the enteritis index D) Group 13, Honokiol $0.6 \mathrm{~g} / \mathrm{kg}$, normal crypt depth. All photos hematoxylin and eosin stain. A\&B 400x; C\&D 100x magnification. mechanism against the compounds $[19,20]$. However, due to the wide variety of modes of action by which phytogenic feed ingredients can influence poultry performance, it is difficult to base a safety conclusion on only general effects and further studies are necessary [21]. Furthermore, despite the increasing numbers of studies investigating the beneficial effects of phytogenic compounds, there is a lack of consideration regarding the safety and residual toxicity of phytogenic compounds, which would ultimately affect translation to commercial use. As such, this study aims to evaluate the target animal safety of Berberine, Ursolic acid, Piceid, Honokiol and Baicalin in poultry, and investigate their effect on performance and intestinal health.

In addition, Berberine is of particular concern as a study conducted by the National Toxicology Program reviews the toxicology and carcinogenicity of its plant source Goldenseal root powder in F344/N and B6C3F1 mice, and concluded that there was clear evidence of carcinogenic activity based on the results of 2-year feeding studies [22]. Increased incidence of hepatocellular adenoma or hepatocellular carcinoma was found in mice given the highest dose of 25,000 ppm Goldenseal root powder, or approximately $3,275 \mathrm{mg} / \mathrm{kg}$ bodyweight for males and $2,875 \mathrm{mg} /$ $\mathrm{kg}$ bodyweight for females. In view of these concerns, this study also aims to assess the human risk when consuming poultry given Berberine in-feed by investigating the tissue residue levels of Berberine and its metabolites in various poultry tissues through LC-MS/MS.

\section{Materials and Methods}

\section{Source of material and animals}

Phytogenic compounds including Berberine Chloride, Ursolic Acid, Piceid, Honokiol and Baicalin were sourced from the Sichuan Yuxin Pharmaceutical Industry Limited Company (Chengdu, China).

The Phase 1 target poultry trial obtained day-of-hatch male Cobb 500 chicks from Cobb-Vantress hatchery, Cleveland, GA. The Phase 2 Berberine Poultry Residue trial obtained day-of-hatch Cobb 500 chicks from Baiada Country Road Hatchery, Tamworth, NSW, Australia. Chicks were vaccinated and initially handled as described by Wu et al. [23].

\section{Phase 1 experimental design}

This trial was performed using one hundred and sixty (160) broiler chicks. Ten (10) male broiler chicks were placed in each pen. The diets were provided ad libitum in one tube-type feeder per pen. Water was provided ad libitum from one Plasson drinker per pen. Standard floor pen management practices were used throughout the experiment. Animals and housing facilities were inspected twice daily, observing and recording the general health status, constant feed and water supply as well as temperature, removing all dead birds, and recognizing unexpected events.

Commercial grade diet was provided and fed as crumbles/pellets. Treatment Starter feed was fed from day 0-21. Grower feed was issued and fed until day 35. Finisher feed was fed until day 42. 
Feed compositions are as depicted in Table 1, and did not contain any probiotic/prebiotic feed additives, NSPases, coccidiostats or antibiotic growth promoter. All diets contained phytase.

Treatment groups are depicted in Table 2. This allowed us to analyze the use of five naturally occurring compounds when administered in the feed in normal farming conditions.

Assessment of effects: Twice daily observations were recorded during the study for general flock condition. Observations included were the availability of feed and water, temperature control, and any unusual conditions. The birds were watched closely for any abnormal reactions. Feed intake, bodyweight (BW) and feed conversion ratio (FCR) were recorded and compared between groups to determine treatment effects. Bodyweight was recorded on day 0 and 42 . The mean initial weight of the chicks for all groups was recorded as not significantly different. FCR was calculated by the following formulae [24].

Table 1 Phase 1 diet composition.

\begin{tabular}{|c|c|c|c|}
\hline & \multicolumn{3}{|c|}{ Commercial grade diet (\%) } \\
\hline Ingredients & Starter & Grower & Finisher \\
\hline CORN, YELLOW, GRAIN & 64.675 & 66.460 & 68.491 \\
\hline $\begin{array}{c}\text { SOYBEAN MEAL DEHULLED, } \\
\text { SOLVENT }\end{array}$ & 29.020 & 26.663 & 24.677 \\
\hline Ampro 55 (animal by-product 55\% & 2.500 & 3.000 & 3.000 \\
\hline $\begin{array}{c}\text { protein) } \\
\text { CALCIUM CARBONATE }\end{array}$ & 0.886 & 0.735 & 0.684 \\
\hline FAT, VEGETABLE & 0.883 & 1.485 & 1.702 \\
\hline DICALCIUM PHOSPHATE. & 0.706 & 0.612 & 0.500 \\
\hline SALT, PLAIN (NaCl) & 0.439 & 0.435 & 0.436 \\
\hline Methionine MHA & 0.358 & 0.259 & 0.221 \\
\hline L - LYSINE & 0.273 & 0.208 & 0.145 \\
\hline L-Threonine 98.5 $^{\text {Trace Mineral }}{ }^{1}$ & 0.103 & 0.000 & 0.000 \\
\hline Vitamin premix $^{2}$ & 0.075 & 0.075 & 0.075 \\
\hline ronozymep-(ct) $^{2}$ & 0.065 & 0.050 & 0.050 \\
\hline & 0.019 & 0.019 & 0.019 \\
\hline
\end{tabular}

Table 2 Phase 1 target poultry safety experimental design.

\begin{tabular}{|c|c|c|c|c|c|}
\hline Group & Bird Type & $\begin{array}{c}\text { Treatment } \\
\text { (in-feed) }\end{array}$ & $\begin{array}{c}\text { Dosage (g/ } \\
\text { kg) }\end{array}$ & $\begin{array}{c}\text { Treatment } \\
\text { Days }\end{array}$ & No. Birds \\
\hline 1 & Broiler & Nil & - & - & 10 \\
\hline 2 & Broiler & Berberine & 0.05 & $0-42$ & 10 \\
\hline 3 & Broiler & Berberine & 0.5 & $0-42$ & 10 \\
\hline 4 & Broiler & Berberine & 1.0 & $0-42$ & 10 \\
\hline 5 & Broiler & Ursolic Acid & 0.005 & $0-42$ & 10 \\
\hline 6 & Broiler & Ursolic Acid & 0.15 & $0-42$ & 10 \\
\hline 7 & Broiler & Ursolic Acid & 1.0 & $0-42$ & 10 \\
\hline 8 & Broiler & Piceid & 0.005 & $0-42$ & 10 \\
\hline 10 & Broiler & Piceid & 0.05 & $0-42$ & 10 \\
\hline 11 & Broiler & Piceid & 0.5 & $0-42$ & 10 \\
\hline 12 & Broiler & Honokiol & 0006 & $0-42$ & 10 \\
\hline 13 & Broiler & Honokiol & 0.06 & $0-42$ & 10 \\
\hline 14 & Broiler & Baicalin & 0.6 & $0-42$ & 10 \\
\hline 15 & Broiler & Baicalin & 0.14 & $0-42$ & 10 \\
\hline 16 & Broiler & Baicalin & 1.0 & $0-42$ & 10 \\
\hline
\end{tabular}

$\mathrm{FCR}=$ (Total feed consumed by birds in a treatment group)/ (Weight gain of surviving birds+Weight gain of dead birds).

Intestinal pathology and pistology: Duodenum, some with pancreas, jejunum, and ileum from chickens at 42 days of age, were submitted fixed in formalin for histologic examination. 2 $\mathrm{mm}$ sections of tissue were trimmed from the submitted tissue, placed in cassettes, and processed for paraffin-embedded $5 \mu \mathrm{m}$ sections stained with hematoxylin and eosin (H\&E). All intestinal sections were kept intact in circular form to ensure uniformity of assessment. Tissues were examined microscopically for lesions and for parasites. A lesion panel was developed for each tissue, and lesions were semi-quantitatively scored for severity per 0 , normal; 1 , minimal severity; 2 , mild severity; 3 , moderate; 4, marked and 5, severe. Coccidia if present were identified to species (if possible) and scored according to previous work $[25,26]$.

For each bird, a coccidia index was calculated by summing the coccidia scores from each section of intestine. A cumulative pathology index was calculated by summing all lesion scores for all sections of intestine. The total enteritis index was calculated by subtracting the coccidia index from the cumulative lesion index, leaving a number representing inflammation and repair.

On the day of study completion (day 42), five (5) birds from each pen were humanely euthanized and upper, mid and lower gut sections plus liver lobe were collected and stored in neutral buffered formalin. These samples were shipped to Veterinary Diagnostic Pathology, LLC for microscopic lesion analysis. Lesions were scored for severity as 0 , lesion absent or within normal; 1, minimal severity; 2 , mild severity; 3 , moderate severity; 4 , marked severity; 5 , severe. Lesion scores were recorded in a spreadsheet. A hepatitis index was calculated by summing all lesion scores from each liver.

\section{Phase 2 experimental design}

A follow-up study was conducted to determine the tissue residues of Berberine when administered orally via feed to commercial broiler chickens. Two concentrations were investigated: $0.3 \mathrm{~g} / \mathrm{kg}$ feed and $0.03 \mathrm{~g} / \mathrm{kg}$ feed, representing high and low concentrations respectively. The trial was performed with one hundred and eighty (180) birds divided into groups of ten birds. As the typical poultry farming collects broilers anytime from days 35 to 42, test birds receiving Berberine for 35 days at either the high or low concentration were divided into groups with different euthanasia times of day $35,36,37,39$ and 42 to simulate the farming process. This also gives an indication of whether elimination (metabolism and excretion) of Berberine was evident due to the incorporation of a washout period.

This was further investigated with the addition of groups receiving Berberine for only 28 days that were euthanized on day 42 to simulate a two-week washout. Feed with Berberine was replaced with regular feed in all cases when appropriate. In all cases, samples were taken from three regions of muscle tissue 
Table 3 Phase 2 Berberine poultry residue experimental design.

\begin{tabular}{|c|c|c|c|c|c|c|}
\hline Group & Bird Type & Treatment (in-feed) & Dosage (g/kg) & Treatment Days & Euthanasia Day & No. Birds \\
\hline 1 & Broiler & $\mathrm{Nil}$ & - & $0-35$ & 35 & 10 \\
\hline 2 & Broiler & Nil & - & $0-35$ & 36 & 10 \\
\hline 3 & Broiler & Nil & - & $0-35$ & 37 & 10 \\
\hline 4 & Broiler & Nil & - & $0-35$ & 39 & 10 \\
\hline 5 & Broiler & Nil & - & $0-35$ & 42 & 10 \\
\hline 6 & Broiler & Nil & - & $0-28$ & 42 & 10 \\
\hline 7 & Broiler & Berberine & 0.03 & $0-35$ & 35 & 10 \\
\hline 8 & Broiler & Berberine & 0.03 & $0-35$ & 36 & 10 \\
\hline 9 & Broiler & Berberine & 0.03 & $0-35$ & 37 & 10 \\
\hline 10 & Broiler & Berberine & 0.03 & $0-35$ & 39 & 10 \\
\hline 11 & Broiler & Berberine & 0.03 & $0-35$ & 42 & 10 \\
\hline 12 & Broiler & Berberine & 0.03 & $0-28$ & 42 & 10 \\
\hline 13 & Broiler & Berberine & 0.3 & $0-35$ & 35 & 10 \\
\hline 14 & Broiler & Berberine & 0.3 & $0-35$ & 36 & 10 \\
\hline 15 & Broiler & Berberine & 0.3 & $0-35$ & 37 & 10 \\
\hline 16 & Broiler & Berberine & 0.3 & $0-35$ & 39 & 10 \\
\hline 17 & Broiler & Berberine & 0.3 & $0-35$ & 42 & 10 \\
\hline 18 & Broiler & Berberine & 0.3 & $0-28$ & 42 & 10 \\
\hline
\end{tabular}

(breast, upper and lower thigh) and the liver. Table 3 summarizes the experimental design showing the concentration of Berberine used and the feeding regimen for each of the 18 groups of birds in the residue study. This data will allow for government regulatory authorities to set appropriate with-holding periods (WHP) to protect both human health and agricultural trade.

Assessment of effects: Feed and water intake, BW, FCR were recorded and compared between groups. The mean initial weight of the chicks of all groups was recorded as not significantly different. Birds were examined for gross visual pathological changes.

Duplicate representative samples of liver, breast muscle, and leg muscle (upper and lower thigh) was collected and stored frozen ( $<10$ degrees Celsius). Three birds from each treated group was analyzed for residues of Berberine, while six birds from the control groups was analyzed. Berberine was assayed by LC-MS/ MS using tetrahydropalmatine as an internal standard $[27,28]$. Performance of the LC-MS/MS was limited to $>5 \mathrm{ng} / \mathrm{g}$, with levels lower than $5 \mathrm{ng} / \mathrm{kg}$ considered below the lower limit of quantification (LLOQ) and cannot be quoted with confidence, while levels lower than $2 \mathrm{ng} / \mathrm{kg}$ are considered to be within baseline noise, below the lower limit of detection (LLOD), and as such are not detectable.

Preparation of tissue samples: Approximately $1 \mathrm{~g}$ of tissues were cut out and weighed into M-tubes. The tissues were stored in a freezer at $-20^{\circ} \mathrm{C}$ until they were ready to be homogenized.

- For each gram of tissue, 2 volumes of MilliQ water was added to the tubes.

- The M-tubes were attached onto the GentleMACS homogenizer and the program method RNA_01_01 (60 seconds) was run 3 times to ensure that the tissue was completely homogenized.
- The tissue homogenates were distributed into Eppendorf tubes in $200 \mu \mathrm{L}$ aliquots.

- To each $200 \mu \mathrm{L}$ aliquot of tissue homogenate, $10 \mu \mathrm{L}$ internal standard solution was added, followed by $600 \mu \mathrm{L}$ of $100 \%$ methanol. Samples were vortexed at maximum setting for $3 \times 10$ seconds and then centrifuged at 10,000 rpm for 3 minutes.

- $100 \mu \mathrm{L}$ of supernatant was transferred into LC vials for analysis.

Method validation: The method was validated for selectivity, linearity, LLOQ, accuracy, precision, recovery, stability and matrix effect.

Selectivity was assessed by preparing samples spiked with individual analyte at concentrations up to $500 \mathrm{ng} / \mathrm{g}$ with 5 replicates each. The peak signal was compared with the calibration standards (spiked with analytes) to ensure that there was no interference.

To evaluate LLOQ, the $5 \mathrm{ng} / \mathrm{g}$ and $10 \mathrm{ng} / \mathrm{g}$ standards were prepared at 6 replicates. The LLOQ was determined at the lowest concentration of the calibration curve which both precision and accuracy were $\leq 20 \%$.

For an indication of accuracy and precision, 4 concentration levels of 20,50, 100 and $500 \mathrm{ng} / \mathrm{g}$ were prepared (5 replicates each). Accuracy was denoted as bias (\%) from the nominal concentration and precision was denoted as the relative standard deviation (RSD) of the replicates.

To evaluate recovery, matrix recovery samples were prepared by extracting blank tissue and then spiking with the analyte solutions to give various concentration levels up to $500 \mathrm{ng} / \mathrm{g}$ ( 5 replicates each). The recovery was defined by the ratio of the mean peak area of extracted samples to the mean peak area of matrix recovery samples. 
To evaluate bench-top stability, 4 concentration levels of 20, 50,100 and $500 \mathrm{ng} / \mathrm{g}$ were prepared at 5 replicates each, where they were kept at room temperature for 30 minutes prior to extraction. The mean peak area was compared to that of freshlyprepared standards.

To evaluate matrix effect (ME), 4 concentration levels of 20, 50, 100 and $500 \mathrm{ng} / \mathrm{g}$ in neat solution were prepared at 5 replicates each. ME was defined as the ratio of the mean peak area of recovery samples to that of the neat standard samples.

\section{Statistical analyses}

Means for weight gain, feed intake, adjusted for mortality feed conversion ratio (FCR), and percent total mortality was calculated. The raw data was analyzed statistically (ANOVA) using a Random Complete Block Design. LSD or Tukey's HSD test ( $p \leq 0.05$ ) was used to separate means when ANOVA $F$ values are significant ( $p$ $\leq 0.05$ ).

\section{Results}

\section{Phase 1 trial results}

Feed intake, FCR and average weight gain: Table 4 summarizes the general effects of five phytogenic compounds in poultry. All birds appeared normal and no adverse effects or unanticipated events occurred. This is reflected in the results showing no ill effects of the compounds on feed intake, FCR or average weight gain. In fact, a slight improvement in FCR when a phytogenic was added to the feed was found when compared to the control group.

Intestinal pathology and liver histology: The effect of the five phytogenic compounds on intestinal pathology is summarized in Table 5. A significant reduction in small enteritis was observed with Honokiol at 0.06 and $0.6 \mathrm{~g} / \mathrm{kg}$ showing greatest decrease compared to control; 3.4 compared to 8.2 respectively. Piceid, Honokiol and Baicalin also resulted in absence of coccidia species

Table 4 Effect of phytogenic compounds on feed intake, fcr and average weight gain summary data.

\begin{tabular}{|c|c|c|c|c|c|}
\hline Group & Treatment (in-feed) & Dosage (g/kg) & Feed Intake (kg) & FCR & Average Weight Gain (kg) \\
\hline 1 & $\mathrm{Nil}$ & - & 33.49 & 1.591 & 2.192 \\
\hline 2 & Berberine & 0.05 & 33.80 & 1.648 & 2.220 \\
\hline 3 & Berberine & 0.5 & 36.44 & 1.639 & 2.386 \\
\hline 4 & Berberine & 1.0 & 30.74 & 1.598 & 2.120 \\
\hline 5 & Ursolic Acid & 0.005 & 35.52 & 1.629 & 2.172 \\
\hline 6 & Ursolic Acid & 0.15 & 31.79 & 1.628 & 2.153 \\
\hline 7 & Ursolic Acid & 1.0 & 35.65 & 1.606 & 2.213 \\
\hline 8 & Piceid & 0.005 & 36.73 & 1.666 & 2.197 \\
\hline 9 & Piceid & 0.05 & 39.79 & 1.693 & 2.342 \\
\hline 10 & Piceid & 0.5 & 33.66 & 1.603 & 2.093 \\
\hline 11 & Honokiol & 0.006 & 30.93 & 1.633 & 2.236 \\
\hline 12 & Honokiol & 0.06 & 33.80 & 1.641 & 2.052 \\
\hline 13 & Honokiol & 0.6 & 32.79 & 1.623 & 2.012 \\
\hline 14 & Baicalin & 0.014 & 35.82 & 1.614 & 2.212 \\
\hline 15 & Baicalin & 0.14 & 36.53 & 1.627 & 2.237 \\
\hline 16 & Baicalin & 1.0 & 33.58 & 1.644 & 2.236 \\
\hline
\end{tabular}

Table 5 Effect of phytogenic compounds on intestinal pathology summary data.

\begin{tabular}{|c|c|c|c|c|c|}
\hline Group & Treatment (in-feed) & Dosage (g/kg) & Enteritis & Coccidia & Cumulative Pathology \\
\hline 1 & Nil & - & 8.2 & 2.6 & 10.8 \\
\hline 2 & Berberine & 0.05 & 6.4 & 3.2 & 9.6 \\
\hline 3 & Berberine & 0.5 & 6.0 & 1.6 & 7.6 \\
\hline 4 & Berberine & 1.0 & 8.2 & 1.0 & 9.2 \\
\hline 5 & Ursolic Acid & 0.005 & 5.8 & 0.2 & 6.0 \\
\hline 6 & Ursolic Acid & 0.15 & 8.2 & 2.0 & 10.2 \\
\hline 7 & Ursolic Acid & 1.0 & 7.6 & 2.4 & 10.0 \\
\hline 8 & Piceid & 0.005 & 7.4 & 3.0 & 10.4 \\
\hline 9 & Piceid & 0.05 & 4.0 & 0.0 & 4.0 \\
\hline 10 & Piceid & 0.5 & 4.6 & 0.0 & 4.6 \\
\hline 11 & Honokiol & 0.006 & 5.4 & 0.2 & 5.6 \\
\hline 12 & Honokiol & 0.06 & 3.4 & 1.8 & 5.2 \\
\hline 13 & Honokiol & 0.6 & 3.4 & 0.0 & 3.4 \\
\hline 14 & Baicalin & 0.014 & 6.0 & 0.0 & 6.0 \\
\hline 15 & Baicalin & 0.14 & 6.2 & 0.0 & 6.2 \\
\hline 16 & Baicalin & 1.4 & 6.0 & 0.0 & 6.0 \\
\hline
\end{tabular}


Table 6 Berberine tissue residue in poultry summary table.

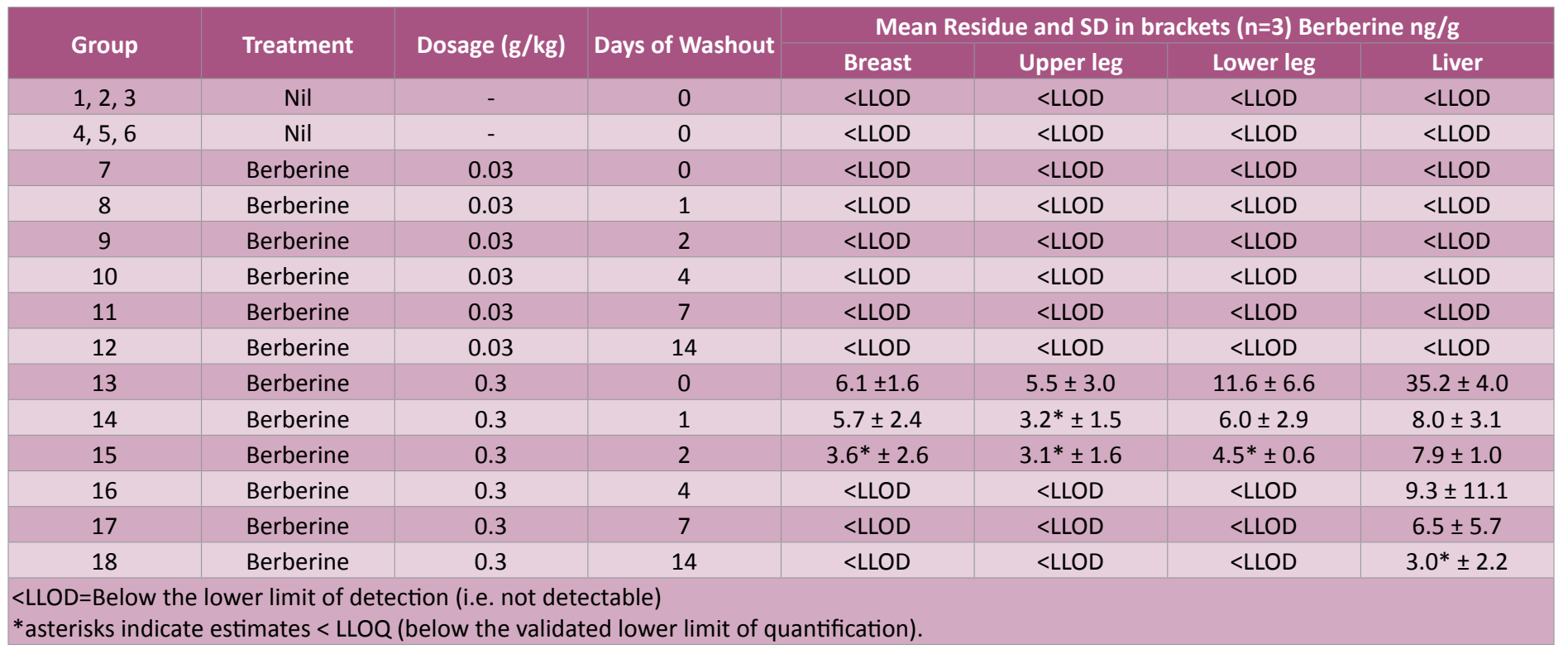

in the gut compared to 2.6 in the controls. All treated groups had cumulative pathology and enteritis scores equal to or lower than the group not treated with a phytogenic compound.

Livers in control and treatment chickens had mild lesions without differences observed in the liver lesion index among groups. These changes included mild lymphocytic hepatitis in the portal regions, and extramedullary hematopoiesis, within normal limits for a production environment.

\section{Phase 2 trial results}

Berberine poultry tissue residue: Table 6 details the Berberine tissue residue in breast muscle, upper and lower leg muscle and liver. Residues of Berberine were detectable and quantifiable after feeding for 35 days at the high Berberine concentration. The mean residue levels $(n=3)$ at the high concentration after 35 days of feeding without washout were $6.1 \mathrm{ng}, 5.5 \mathrm{ng}, 11.6$ $\mathrm{ng}$ and $35.2 \mathrm{ng}$ per gram of tissue in breast, upper leg, lower leg and liver respectively. A washout effect was evident at the high concentration in liver and all three muscle tissues. This washout resulted in muscle tissue levels below the LLOD after 4 days of washout. Berberine levels were quantifiable in liver up to 7 days of washout ( $6.5 \mathrm{ng} / \mathrm{g}$ after 7 days) but were below the validated LLOQ after 14 days of washout $(3.0 \mathrm{ng} / \mathrm{g})$. At the low concentration, the mean residue levels were lower than $2 \mathrm{ng} / \mathrm{g}$ i.e. below the LLOD, in all cases in all tissues, with or without washout.

\section{Discussion}

Phytogenic compounds have the potential to contribute to general health management and disease control of poultry. They hold advantages in that they can be administered from day-ofhatch and are relatively easy to translate to commercial use. Thousands of phytogenic compounds have also been identified as inhibitory towards microorganisms [29]. However, the limited in vivo data and sometimes contradictory findings, suggest it cannot be univocally determined what contribution phytogenic feed ingredients may offer [30]. This study hopes to provide further insight into the feasibility of phytogenic compounds, particularly Berberine, as feed ingredients for the poultry industry by conducting a general target poultry safety study with five phytogenic compounds, and for the first time, assessing the tissue residue of Berberine in poultry to aid regulatory institutes such as the APVMA and FDA in setting the optimal method for Berberine use in poultry.

The Phase 1 in vivo trial demonstrates that Berberine, Ursolic Acid, Piceid, Honokiol and Baicalin are not harmful even at the highest concentration tested of $1.0 \mathrm{~g} / \mathrm{kg}$ in-feed. In fact, the results show an improvement in FCR although conclusions cannot be drawn due to the lack of statistical significance. Nevertheless, there has been accumulating evidence that phytogenics can modulate the gut microbiota to confer beneficial effects [31]. This is reflected in the cumulative pathology scores, where the phytogenic compounds markedly reduced enteritis and coccidia lesions, and further supported by recent studies reporting the anticoccidial effect of Berberine and its activity against Clostridium Perfringens in poultry [8,9], antimicrobial activity of Ursolic Acid in irradiated fresh poultry $[11,12]$, improved poultry performance of birds treated with Piceid [14-16], improved performance in birds using Honokiol, and activity of Baicalin against Candida Albicans [32]. However, despite the apparent positive effects of the phytogenic compounds, the gastrointestinal histologic lesions identified were within normal limits for broiler chick in a production environment, as were the liver histological lesions. Therefore, while no conclusions can be made regarding the activity of the compounds tested, there is evidence to presume that they pose no harm to commercial broilers.

The Phase 2 Berberine tissue residue study shows that the lower concentration $0.03 \mathrm{~g} / \mathrm{kg}$ in-feed had no detectable Berberine residue in the breast, upper and lower thigh, and liver. This is the case with or without washout periods, when the LLOD was 
$2 \mathrm{ng} / \mathrm{g}$. However, the higher concentration of $0.3 \mathrm{~g} / \mathrm{kg}$ had clear residue profiles, particularly in the liver. There was also a correlation between number of washout days and residue amount, with increased number of washout days resulting in decreased residue. The greatest amount of Berberine tissue residue was $35.2 \mathrm{ng} / \mathrm{g}$, and found in the liver of birds treated with $0.3 \mathrm{~g} / \mathrm{kg}$ in-feed with no washout.

The significance of these results are not yet clear, as the underlying concern was that Berberine residue in poultry meat would prove to be potentially carcinogenic to humans based on a toxicology study performed on Goldenseal root powder [22]. At the very least, the low concentration of Berberine looks to be readily feasible due to the negligible tissue residue found ( $<L L O D=<2.0 \mathrm{ng} / \mathrm{kg}$ ), although it would be ideal if further exposure and risk assessment calculations are performed to clarify both concentrations of Berberine usage as a feed ingredient for broilers and safety for humans consuming foods derived from broilers fed Berberine-containing feed.

In conclusion, this study shows that Berberine, Ursolic Acid, Piceid, Honokiol and Baicalin caused no discernible adverse effect in poultry when administered as an ingredient in-feed. Interestingly, the study results suggest there is potential for better production performance and general health of poultry with the tested phytogenic compounds showing slight improvement

\section{References}

1 Kostyanev TMJ, Bonten H, Goossens F (2017) A Review on Antimicrobial Resistance publication suggested 10 crucial recommendations in their final report to tackle antimicrobial resistance, including an emphasis on the importance of increased awareness, infection prevention, better use of existing treatments, and reducing. Anti-infectives and the Lung: ERS Monograph 75: 289.

2 Leyte-Lugo M (2017) Secondary metabolites from the leaves of the medicinal plant goldenseal (Hydrastis canadensis). Phytochemistry Letters 20: 54-60.

3 Imanshahidi M, Hosseinzadeh $\mathrm{H}$ (2008) Pharmacological and therapeutic effects of Berberis vulgaris and its active constituent, berberine. Phytotherapy research 22: 999-1012.

4 Xu JL, Wang L, Xu B (2004) Research development of Coptis chinensis. Zhongguo yi xue ke xue yuan xue bao. Acta Academiae Medicinae Sinicae 26: 704-707.

5 Cordell GA, Quinn-Beattie ML, Farnsworth NR (2001) The potential of alkaloids in drug discovery. Phytotherapy Research 15: 183-205.

6 Feng R (2016) Antibacterial activity and mechanism of berberine on avian Pasteurella multocida. International Journal of clinical and experimental medicine 9:22886-22892.

7 Fang Z (2016) Protective effect of berberine on the intestinal caecum in chicks with Eimeria tenella. Avian Biology Research 9(4): 235-239.

8 Malik TA (2016) Synergistic approach for treatment of chicken coccidiosis using berberine-A plant natural product. Microbial pathogenesis 93: 56-62.

9 David Y (2017) The Effects of Berberine on Clostridium Perfringens Induced Necrotic Enteritis in Broiler Chickens. Archives of Clinical in performance and intestinal pathology. However, practical application is still limited due to lack of efficacy reports and insufficient understanding of the modes of action. Finally, despite $0.03 \mathrm{~g} / \mathrm{kg}$ Berberine in-feed resulting in no detectable residue in the breast, thighs and liver of treated birds, further evaluation of potential risks to human health with not only Berberine but other phytogenics is necessary in terms of contamination, exposure and risk assessment.

\section{Acknowledgements}

This research was conducted with the help of the Southern Poultry Research, Inc. Georgia, USA and Veterinary Health Research Ltd, Armidale, NSW, Australia. We are thankful to Greg Mathis, Charles Hofacre and Bruce Chick for their assistance and expertise. Any errors are our own and should not tarnish the reputations of these esteemed professionals.

\section{Funding}

This research was supported by iRiccorgpharm Pty Ltd in its initiative to reduce antibiotic usage in livestock.

\section{Competing and Conflicting Interests}

This report may be used as supporting data for iRiccorgpharm Pty Ltd phytogenic dossier for regulatory approval.

Microbiology 8 ni Rad, Toxicology effects of Berberis vulgaris (barberry) and its active constituent, berberine: a review. Iranian Journal of Basic Medical Sciences 20: 516.

10 Eevuri TR, Putturu R (2013) Use of certain herbal preparations in broiler feeds-A review. Veterinary World 6 .

11 Mahrour A (1998) Antimicrobial properties of natural substances in irradiated fresh poultry. Radiation Physics and Chemistry 52: 81-84.

12 Lira W (2008) Modulatory effect of Byrsonima basiloba extracts on the mutagenicity of certain direct and indirect-acting mutagens in Salmonella typhimurium assays. Journal of medicinal food 11: 111-119.

13 Alam GM (2015) A wide variety of animal species Several studies carried out on diets. International Journal of Pharmacology 100 213-221.

14 Kim D (2015) Effects of dietary resveratrol on growth performance, blood biochemical parameter, immunoglobulin, and blood antioxidant activity in broiler chicks. Korean Journal of Poultry Science 42: 147-156.

15 Sridhar MR, Suganthi M, Thammiaha J (2015) Effect of dietary resveratrol in ameliorating aflatoxin B1-induced changes in broiler birds. Journal of animal physiology and animal nutrition 99: 10941104.

16 Liu JY (2013) Intestinal absorption and bioavailability of traditional Chinese medicines: a review of recent experimental progress and implication for quality control. Journal of Pharmacy and Pharmacology 65: 621-633.

17 Ding RB (2012) Herbal medicines for the prevention of alcoholic liver disease: a review. Journal of ethnopharmacology 144: 457-465.

18 Suresh G (2017) Alternatives to antibiotics in poultry feed: molecular perspectives. Critical Reviews in Microbiology 11: 1-18. 
19 Fascina V (2017) Effects of Phytogenic Additives and Organic Acids, alone or in combination, on the Performance, Intestinal Quality and Immune Responses of Broiler Chickens. Revista Brasileira de Ciência Avícola 19: 497-508.

20 Van der Aar PF, Molist F, van der Klis J (2016) The central role of intestinal health on the effect of feed additives on feed intake in swine and poultry. Animal Feed Science and Technology 16: 152.

21 Program NT (2010) Toxicology and carcinogenesis studies of goldenseal root powder (Hydrastis Canadensis) in F344/N rats and B6C3F1 mice (feed studies). National Toxicology Program technical report series 12: 156 .

22 Wu S, Rodgers K, Choct L (2010) Optimized necrotic enteritis model producing clinical and subclinical infection of Clostridium perfringens in broiler chickens. Avian diseases 54: 1058-1065.

23 Kalavathy R (2003) Effects of Lactobacillus cultures on growth performance, abdominal fat deposition, serum lipids and weight of organs of broiler chickens. British Poultry Science 44: 139-144.

24 Al-Sheikhly F, A. Al-Saieg R (1980) Role of coccidia in the occurrence of necrotic enteritis of chickens. Avian diseases 14: 324-333.

25 Lanckriet A (2010) The effect of commonly used anticoccidials and antibiotics in a subclinical necrotic enteritis model. Avian Pathology 39: 63-68.

26 Ding B (2007) Qualitative and quantitative determination of ten alkaloids in traditional Chinese medicine Corydalis yanhusuo WT Wang by LC-MS/MS and LC-DAD. Journal of pharmaceutical and biomedical analysis 45: 219-226.

27 Li L (2006) Liquid chromatography-tandem mass spectrometry for the identification of I-tetrahydropalmatine metabolites in Penicillium janthinellum and rats. Biomedical Chromatography 20: 95-100.

28 Cowan MM (1999) Plant products as antimicrobial agents. Clinical microbiology reviews 12: 564-582.

29 Hermans D (2011) Campylobacter control in poultry by current intervention measures ineffective: urgent need for intensified fundamental research. Veterinary microbiology 152: 219-228.

30 Perić L (2010) Effects of probiotic and phytogenic products on performance, gut morphology and cecal microflora of broiler chickens. Archiv fur Tierzucht 53: 350-359.

31 Xiong Y (2004) Study on activity and mechanism of baicalin against candida albicans [J]. Chinese Pharmacological Bulletin 12: 1020. 